\title{
Sequential radiological and surgical management of tubo-ovarian abscess: a success story
}

\author{
Nikita Naredi $^{1 *}$, Vipin Kumar Prajapati², Nilesh Mhaske ${ }^{1}$, Neha Sahay ${ }^{3}$
}

\begin{abstract}
${ }^{1}$ Department of Obstetrics and Gynaecology, Military Hospital, Bhopal, Madhya Pradesh, India ${ }^{2}$ Department of Obstetrics and Gynaecology, Armed Forces Medical College, Pune, Maharashtra, India ${ }^{3}$ Department of Obstetrics and Gynaecology, Military Hospital, Nasirabad, Ajmer, Rajasthan, India
\end{abstract}

Received: 24 March 2021

Revised: 03 May 2021

Accepted: 04 May 2021

\author{
*Correspondence: \\ Dr. Nikita Naredi, \\ E-mail: nikitanaredi@gmail.com
}

Copyright: (c) the author(s), publisher and licensee Medip Academy. This is an open-access article distributed under the terms of the Creative Commons Attribution Non-Commercial License, which permits unrestricted non-commercial use, distribution, and reproduction in any medium, provided the original work is properly cited.

\section{ABSTRACT}

A tubo-ovarian abscess (TOA) is a complex mass of infectious etiology in the adnexa forming as a sequela of pelvic inflammatory disease (PID). If the abscess ruptures, there is a risk of life-threatening infection. Thus, it requires great degree of suspicion for the correct diagnosis followed by prompt evaluation and treatment. This case is reported with the aim to describe the unusual presentation of TOA without a significant history of PID and the unconventional way of TOA drainage.

Keywords: TOA, Tubo-ovarian abscess, PID

\section{INTRODUCTION}

Tubo-ovarian abscess term is used to describe an abscess incorporating the fallopian tube and ovary and it develops as a consequence of an infectious process leading to pus collection involving adnexa. This infection is usually polymicrobial and is composed of anaerobic and gramnegative bacteria, that ascends to the pelvic space. TOA occurs in the context of PID in about $30 \%$ of cases. TOA is defined as primary when it occurs along with PID and secondary if it occurs as a consequence of other intraabdominal processes, like perforation of bowel or gynecological malignancy. ${ }^{1}$

The diagnosis of TOA is made by clinical examination, laboratory investigation and imaging. The most consistent symptom is abdomino-pelvic pain. The principal sign is uterine tenderness. Laboratory investigations will reveal elevation of leucocyte counts and inflammatory markers (C-reactive protein). The gold standard investigation for the diagnosis of TOA is Transvaginal ultrasound (TVS).
TVS findings will be suggestive of TOA include a complex and cystic neo-formation in the pelvic region with heterogeneous appearance and irregular margins with increased surrounding vascularity associated with high resistance index in Doppler study. ${ }^{2}$

In the past TOAs were a cause of significant morbidity and mortality and the standard treatment was surgery using a laparotomy approach.

Currently, the treatment of TOA requires introduction of parenteral broad spectrum antibiotics therapy. The early diagnosis and the advent of these therapies permitted medical treatment success in about $70-75 \%$ of cases. ${ }^{3,4}$ The other $25-30 \%$ of cases require surgical drainage, using minimally invasive surgical approaches, such as laparoscopic drainage or ultrasound guided transvaginal puncture and drainage. ${ }^{5}$

This case has a rare presentation of tubo- ovarian abscess without any risk factors and the unusual management by 
draining the pus using ovum pickup needle followed by definitive management.

\section{CASE REPORT}

Our patient is a 45-year-old woman who presented with two days history of severe lower abdominal pain. There was no history of fever, nausea or vomiting. She is para2 living2 with no significant gynecological history. Her last menstrual period started 2 days before admission. She was a known case of hypertension and blood pressure controlled on drugs. Physical examination revealed tachycardia, but blood pressure and temperature within normal limits. Abdominal examination elicited tenderness in the left iliac and suprapubic region, however no obvious mass could be felt due to obesity and bowel sounds were normal. Bimanual vaginal examination revealed bogginess and fullness in the fornices but boundaries of the mass could not be felt, uterus was not palpable separately and groove sign was absent. Laboratory parameters revealed a WBC count of $22670 / \mathrm{mm} 3$, hemoglobin of $10.3 \mathrm{~g} / \mathrm{dl}$, platelet count of $528,000 / \mathrm{mm} 3$ and CRP positive. Her CA125 was $69.1 \mathrm{U} / \mathrm{ml}$ and other tumor markers were within normal range.

Transvaginal sonography showed large bulky uterus pulled anterosuperiourly with elongated cervix and multiple myomas. Left ovary was incorporated within a large left adnexal cystic mass demonstrating convoluted tubular cystic areas and a retort shaped cystic area full with fine soft echoes and increased vascularity on Doppler. CECT pelvis revealed bulky uterus with multiple fibroids and a thin walled multiloculated cystic lesions in left adnexal region measuring $6.1 \times 6.6 \times 7.6 \mathrm{~cm}$, showing evidence of fallopian tube dilatation measuring $18-20 \mathrm{~mm}$ in caliber. Left ovary not separately visualized. Right ovary appears normal.

On the basis of these imaging and clinical findings, a diagnosis of tubo-ovarian abscess was made, and the patient was admitted for treatment by the gynecology service. After blood and urine cultures were obtained, patient was started on IV antibiotic therapy using meropenem, clindamycin and oral doxycycline. Despite 24 hrs. of antibiotic treatment, the patient remained symptomatic. In view of this, the possibility of radiological drainage of the tubo-ovarian abscess was made. Under anesthesia $200 \mathrm{ml}$ of foul-smelling pus was drained using ovum pickup needle. The patient though had symptomatically relieved and leukocytosis was decreased but the persistence of symptoms prompted us to take a decision for laparotomy and proceed was made due complains of persistent lower abdomen pain by patient.

On laparotomy uterus was found to be plastered with anterior abdominal wall. No pus was found in abdominal cavity. Left TO mass was separated from gut, omentum and left salpingo-ophrectomy was done. Uterus had multiple small fibroids. Right tube and ovaries were normal. Post operatively patient improved drastically with a gradual decrease in leukocytosis returning to normal limits. Post op period was uneventful. Suture removal done on day 8 and patient was discharged on day 10 . Histopathological report revealed tub-ovarian abscess.

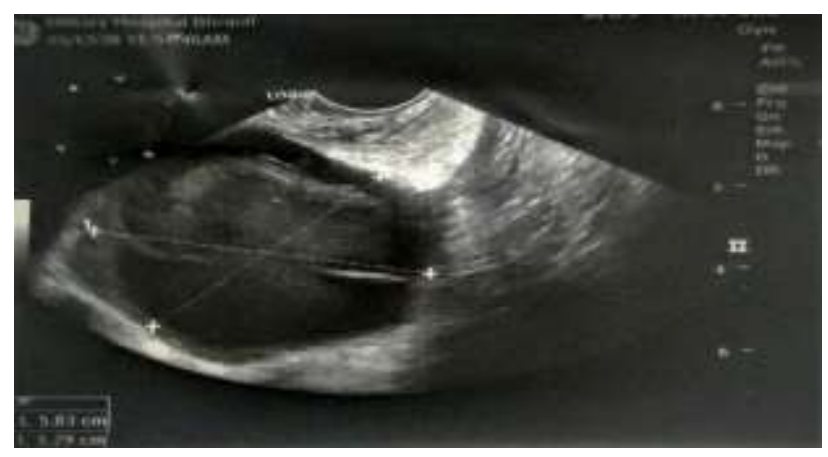

Figure 1

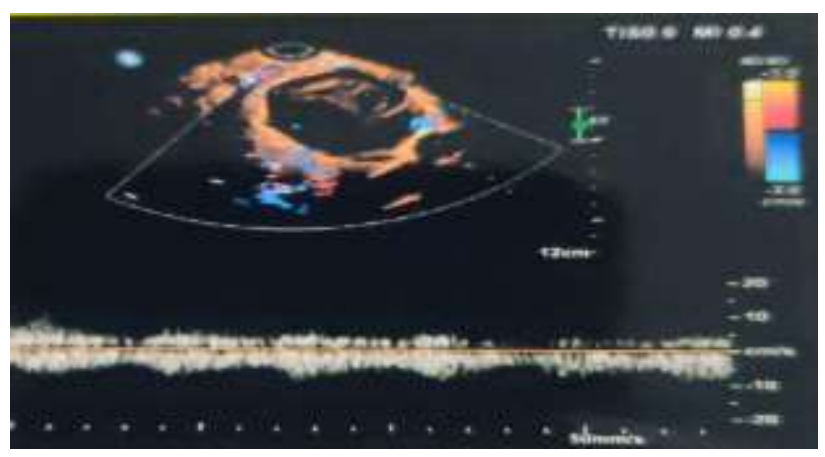

Figure 2

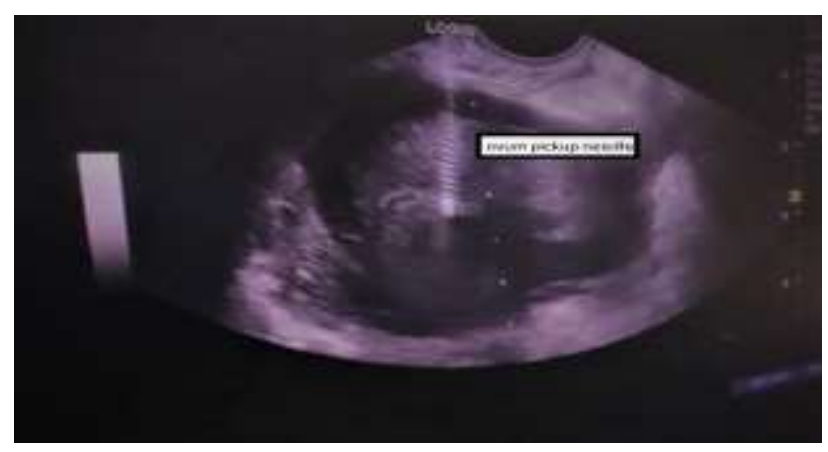

Figure 3

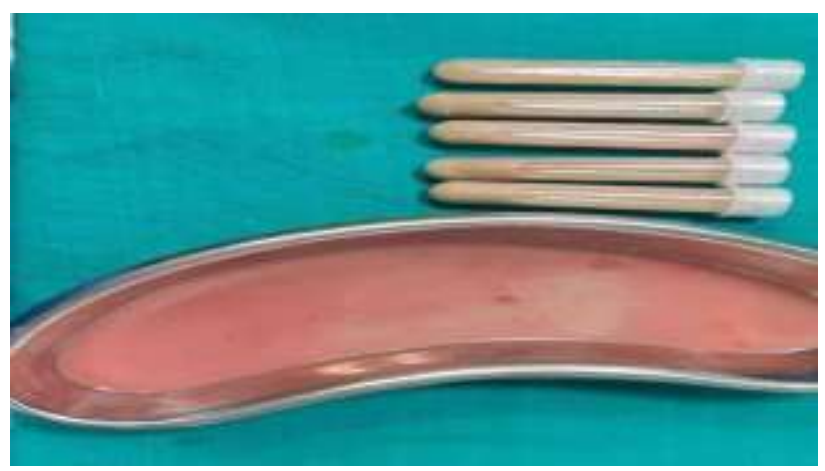

Figure 4 


\section{DISCUSSION}

Tubo-ovarian abscess is a serious complication of PID. It occurs usually in women aged 20-49 years and carries a significant risk of morbidity and mortality. PID is more common in young age but the mean age of patients presenting with TOA was 37.8 years with $\sim 43 \%$ in the age group of $40-49$ years and $6.9 \%$ in the age group of $>50$ years. ${ }^{6}$ The mechanisms by which TOAs are formed have been difficult to establish due to different presentations and degrees of tubo-ovarian damage present when the infection is diagnosed. It seems clear that TOAs are often the consequence of PID. However, in few women with TOA, no symptoms or signs of STI/STD can be traced. ${ }^{7}$ Our patient also didn't have any associated risk factors like PID, STD, history of any gynecological interventions.

Most patients with tubo-ovarian abscesses recover with IV antibiotic therapy. Aside from this, TOA may also be treated by drainage under ultrasound guidance or laparoscopy, as well as laparotomy. Drainage of the abscess is indicated in those that do not respond within 23 days of treatment. Drainage is traditionally performed using surgery. Recent improvements in high resolution imaging capabilities and specialized interventional equipment have made radiologic drainage of tubo-ovarian abscess possible. Radiologic drainage is minimally invasive, easy to perform and avoids the potentially higher risks associated with laparotomy. Many studies have been published defending the imaging-guided drainage procedure as the first line to TOA treatment, if the patient is stable and without peritonitis. ${ }^{8,9}$ In our case too we carried out drainage under USG guidance but we used ovum pickup needle/ oocyte retrieval set for ultrasound guided drainage of abscess which is safe, easy to perform and time saving. Approximately $25 \%$ of patients with TOA will require surgical management. Larger TOA have been shown to respond better to surgical management. The size of TO abscess in our case was approx. $8 \mathrm{cms}$ so after drainage left salpingo-oophorectomy was carried out. Although on laparotomy no pus was found in abdominal cavity which shows the effectiveness of drainage of pus using ovum pickup needle.

\section{CONCLUSION}

Our case study represents effective and unconventional way of drainage of TOA. We learn from this report that TOA cases might present without a significant history of other gynecological disorders or interventions. We should always have a high index of suspicion while diagnosing TOA, as it could be life threatening if not managed properly.

\section{Funding: No funding sources Conflict of interest: None declared \\ Ethical approval: Not required}

\section{REFERENCES}

1. Gradison M. Pelvic inflammatory disease. Am Fam Phys. 2012;85(2012):791-6.

2. Oride A, Kanasaki H, Miyazaki K. Therapeutic process of gynecological pelvic abscess retrospective review of 20 cases. Surg Sci. 2013;4(3):202-9.

3. Dewitt J, Reining A, Allsworth JE, Peipert JF. Tuboovarian abscesses: is size associated with duration of hospitalization \& complications? Obstet Gynecol Int. 2010;2010:847041.

4. Stanley K, Morato D, Chilstrom M. Ultrasound diagnosis of bilateral tubo-ovarian abscesses in the emergency department. West J Emerg Med. 2013;14(6):641-2.

5. T. Perez-Medina, M.A. Huertas, J.M. Baio Early ultrasound-guided transvaginal drainage of tuboovarian abscesses: a randomized study. Ultrasound Obstet Gynecol. 1996;7(1996):435-8.

6. Halperin R, Levinson O, Yaron M, Bukovsky I, Schneider D. Tubo-ovarian abscess in older women: is the woman's age a risk factor for failed response to conservative treatment? Gynecol Obstet Invest. 2003;55(4):211-5.

7. Granberg S, Gjelland K, Ekerhovd E. The management of pelvic abscess. Best Pract Res Clin Obstet Gynaecol. 2009;23(5):667-78.

8. Corsi PJ, Johnson SC, Gonik B, Hendrix SL, McNeeley SG Jr, Diamond MP. Transvaginal ultrasound-guided aspiration of pelvic abscesses. Infect Dis Obstet Gynecol. 1999;7(5):216-21.

9. Garbin O, Verdon R, Fauconnier A. [Treatment of tubo-ovarian abscesses]. J Gynecol Obstet Biol Reprod (Paris). 2012;41(8):875-85.

Cite this article as: Naredi N, Prajapati VK, Mhaske N, Sahay N. Sequential radiological and surgical management of tubo-ovarian abscess: a success story. Int J Reprod Contracept Obstet Gynecol 2021;10:2541-3. 